\title{
Activation-induced cytidine deaminase prevents pro-B cell acute Iymphoblastic leukemia by functioning as a negative regulator in Rag1 deficient pro-B cells
}

\author{
Franziska Auer ${ }^{1}$, Deborah Ingenhag ${ }^{1}$, Stefan Pinkert ${ }^{1}$, Sven Kracker ${ }^{2,3}$, Salima \\ Hacein-Bey-Abina4,5, Marina Cavazzana2,3, Michael Gombert ${ }^{1}$, Alberto Martin- \\ Lorenzo $^{6,7}$, Min-Hui Lin ${ }^{1}$, Carolina Vicente-Dueñas ${ }^{7}$, Isidro Sánchez-García ${ }^{6,7}$, \\ Arndt Borkhardt ${ }^{1}$ and Julia Hauer ${ }^{1}$ \\ ${ }^{1}$ Department of Pediatric Oncology, Hematology and Clinical Immunology, Heinrich-Heine University Duesseldorf, Medical \\ Faculty, Duesseldorf, Germany \\ 2 Université Paris Descartes, Sorbonne Paris Cité, Imagine Institute, Paris, France \\ ${ }^{3}$ INSERM UMR 1163, Human Lymphohematopoiesis Laboratory, Paris, France \\ 4 UTCBS CNRS UMR 8258, INSERM U1022, Faculté de Pharmacie de Paris, Université Paris Descartes, Sorbonne Paris Cité, \\ Chimie Paris-Tech, Paris, France \\ ${ }^{5}$ Clinical Immunology Laboratory, Groupe Hospitalier Universitaire Paris-Sud, Hôpital Kremlin-Bicêtre, Assistance Publique- \\ Hôpitaux de Paris, Le-Kremlin-Bicêtre, France \\ ${ }^{6}$ Experimental Therapeutics and Translational Oncology Program, Instituto de Biología Molecular y Celular del Cáncer, CSIC/ \\ Universidad de Salamanca, Campus M. de Unamuno s/n, Salamanca, Spain \\ ${ }^{7}$ Institute of Biomedical Research of Salamanca, Salamanca, Spain \\ Correspondence to: Julia Haver, email: Julia.Haver@med.uni-duesseldorf.de
}

Keywords: acute lymphoblastic leukemia, activation induced cytidine deaminase, pro-B cells, Ragl deficiency

Received: July 27, $2017 \quad$ Accepted: July 31, $2017 \quad$ Published: September 07, 2017

Copyright: Auer et al. This is an open-access article distributed under the terms of the Creative Commons Attribution License 3.0 (CC BY 3.0), which permits unrestricted use, distribution, and reproduction in any medium, provided the original author and source are credited.

\section{ABSTRACT}

Activation-induced cytidine deaminase (AID) is essential for somatic hypermutation and class switch recombination in mature B-cells, while AID was also shown to play a role in developing pre-BCR/BCR-positive B-cells of the bone marrow. To further elucidate a potential function of Aid in the bone marrow prior to $V(D)$ J-recombination, we utilized an in vivo model which exerts a B-cell developmental arrest at the pro-B cell stage with low frequencies of pro-B cell acute lymphoblastic leukemia (pro-B ALL) development. Therefore, p19Arf ${ }^{/-}$Rag1 $^{-/-}$(AR) mice were crossed with Aid-deficient mice (ARA). Surprisingly, loss of Aid expression in pro-B cells accelerated pro-B ALL incidence from $30 \%$ (AR) to $98 \%$ (ARA). This effect was Aid dose dependent, since Aid $^{+/-}$animals of the same background displayed a significantly lower incidence (83\%). Furthermore, B-cell-specific Aid up-regulation was observed in Aid-competent pro-B ALLs. Additional whole exome/sanger sequencing of murine pro-B ALLs revealed an accumulation of recurrent somatic Jak3 (p.R653H, p.V670A) and Dnm2 (p.G397R) mutations, which highlights the importance of active IL7R signaling in the pro-B ALL blast cells. These findings were further supported by an enhanced proliferative potential of ARA pro-B cells compared to Aid-competent cells from the same genetic background. In summary, we show that both Aid and Rag1 act as a negative regulators in pro-B cells, preventing pro-B ALL.

\section{INTRODUCTION}

Over the last decade, various studies gave novel insights that improved our understanding about the molecular basis of childhood acute lymphoblastic leukemia (ALL) [1-5]. Genomic alterations are implicated in disease progression of $\mathrm{B}$-cell precursor ALL, and $R A G 1$ is the key player in this context [6-11]. Unexpectedly, 
RAG1 loss of function mutations were detected in bone marrow (BM) samples of ALL patients despite the presence of several genomic copy number alterations [12], which suggests that molecules other than RAG1 are able to induce genomic alterations in the respective blast cells. In addition to the recombination-activating genes RAG1 and RAG2, which are responsible for V(D)J-recombination [13], the activation-induced cytidine deaminase (AID) enzyme is necessary to produce the secondary repertoire of antibodies in germinal center B-cells [14]. By deaminating cytosine residues in Ig variable as well as switch regions, AID is responsible for somatic hypermutation (SHM) and class-switch recombination (CSR) $[15,16]$.

While AID expression was shown to have implications in B-cell lymphomas [17, 18], which resemble a mature B-cells stage, aberrant AID activity could furthermore be linked to BCR-ABL positive leukemia [19], a disease affecting B-cell precursors. Although the role of AID has been elaborately studied in the context of germinal center B-cells, recent evidence highlighted how AID already exerts a functional role in developing B-cells $[8,20]$. While it was shown that the concurrent expression of AID and RAG1 in small preBII cells contributes to the clonal evolution of childhood ALL in the presence of strong inflammatory stimuli [8], absence of AID expression in pre-BI and immature B-cells has been reported to confer implications in the control of self-tolerance, as shown in both mice and humans [2025]. Up to now, functional AID expression in the BM could be detected in small pre-BII [8], early immature [26] and transitional-1 B-cells [27, 28]. Whether AID is already utilized by earlier B-cell precursors that do not express a precursor B-cell receptor (pre-BCR) is still controversially discussed. In order to elucidate whether Aid is indeed functional prior to pre-BCR expression, we developed an Aid-deficient mouse model with a tumor prone $\mathrm{Ragl}^{-/-}$background (p19Arf/- $\mathrm{Ragl}^{-/} \mathrm{Aid}^{-/-}$ARA). Utilizing this model, we were able to assess the influence of Aid at the pro-B cell stage [29], in the context of pro-B ALL development [30] and in the absence of Rag1 induced alterations. Here, we present in vivo evidence, that the combined absence of Aid and Ragl in tumor prone murine pro-B cells accelerates pro-B ALL incidence, which suggests a functional role of Aid in Rag1 deficient $\mathrm{BM}$ pro-B-cells even before the expression of a pre-BCR.

\section{RESULTS}

\section{Aid is a negative regulator of pro-B ALL development in $\operatorname{Rag}^{-1 /}$ tumor-prone mice}

In order to explore the physiological relevance of Aid at the pro-B cell stage, and independent of Rag1 off-target activity, we designed a mouse model which allows the investigation of an arrested tumor-prone pro-B cell population in combination with Aid deficiency. Aid knockout mice $\left(\mathrm{Aid}^{-/}\right)$were crossed with $\mathrm{pl}$ A $\mathrm{Arf}^{--} \mathrm{Ragl}^{-/-}$ (AR) mice to obtain p19Arf ${ }^{-} \operatorname{Ragl}^{-/-} \mathrm{Aid}^{-/}$(ARA) and p19Arf ${ }^{-}$Ragl $^{-/-}$Aid $^{+/-}$(ARa) mice. P19Arf ${ }^{-}$Ragl $^{-/}$mice are known to develop pro-B ALL at a rate of $26 \%$ [30], which we were able to reproduce in our own independent cohort that showed a pro-B ALL incidence of $30 \%$ (Figure 1A). Surprisingly, concomitant Aid deficiency accelerated the pro-B ALL incidence to 98\% (Log-rank test $p<0.001)$. Moreover, this effect was shown to be Aid dose dependent, since the Aid heterozygous (ARa) animals of the same background displayed significantly lower pro-B ALL development $(83 \%$, Log-rank test $p=$ 0.0167 ) (Figure 1A). Other disease phenotypes observed in ARa animals included solid tumors (5.56\%) and myeloproliferative diseases (11.11\%), while AR animals predominantly developed solid tumors in contrast to the pro-B ALLs in ARA mice [30] (Figure 1B). The leukemias manifested with splenomegaly (Figure $1 \mathrm{C}$ and Supplementary Figure 4A), disrupted splenic architecture related to blast cell infiltration (Figure 1D), and appeared in the peripheral blood (PB) (Figure 1E). FACS analysis revealed a pro-B cell surface phenotype $\mathrm{CD} 19^{+} \mathrm{ckit}^{+} \mathrm{IgM}^{-}$ for blast cells, which extended through BM, PB and spleen (Supplementary Figure 1-3). Moreover, pro-B ALLs were able to engraft in secondary recipients with a phenotype identical to the primary disease and a latency of 1-2 weeks (Figure 1F). V(D)J-recombination assays verifying only the presence of the $\mathrm{c} \mu$ chain were performed to ensure that the model was not leaky, and that pro-B ALL was not derived from mature AID-expressing B-cells which had undergone V(D)J-recombination (Figure $1 \mathrm{G}$ and Supplementary Figure 4B). Hence, the leukemia arose from pro-B cells, which were unable to undergo Rag1mediated V(D)J-recombination. These results suggest a dose-dependent and protective Aid function in Rag $1^{-/}$ pro-B cells even before the development of a functional pre-BCR.

\section{Reduced Aid expression correlates with pro-B ALL incidence in $\operatorname{Rag}^{-1 /}$ tumor-prone mice}

Thus far, it has been proposed that physiologic AID expression in the BM is restricted to $\mathrm{CD} 19^{+} \mathrm{B}$-cells, which co-express a functional IgM heavy chain product [22], since AID transcripts are first detected in pre-BII and immature B-cells, but not in earlier B-cell precursor populations [8]. Here, we show that Aid is expressed in tumors from $\mathrm{pl}^{\mathrm{A}} \mathrm{Arf}^{/-} \mathrm{Ragl}^{-/-}$(AR) mice, which were classified as Hardy Fractions B, resembling a pro-B stage [30]. While no Aid expression was detected in sorted $\mathrm{B} 220^{+} \mathrm{BM}$ cells from healthy AR mice (data not shown), significant Aid expression was observed in AR pro-B ALLs (Figure 2A). The presence of Aid was further 
confirmed on protein level using immunoblotting (Figure 2B and Supplementary Figure 4D). Moreover, the detected Aid expression was shown to be dose dependent, since in ARa pro-B ALLs Aid expression was 10-30 times lower compared to AR leukemias (Figure 2A). In AR and ARa mice, a small proportion of T-ALL and myeloid neoplasia occurred with no detectable Aid expression and, therefore, we consider Aid expression to be B-cell specific (Figure 2A and Supplementary Figure 4C). Further microarray analysis comparing ARA to AR pro-B ALLs validated a differentially regulated gene expression profile between both groups (1774 genes significantly up and 1566 genes significantly down) (Figure 2C and Supplementary Table
1). Since the reduction and loss of Aid expression at the Rag1 deficient pro-B cell stage accelerated the leukemia incidence, we suggest Aid expression as a negative regulator in Rag1 deficient pro-B cells to clear preleukemic populations.

\section{Murine tumor profiling reveals somatic mutations influencing the IL7R/Jak3/Stat5-axis}

To elucidate structural aberrations of the pro-B leukemias, copy number variation analysis of three ARA, three ARa and one AR tumor sample was carried out. Thereby, Chr. 14 amplifications were recurrently detected

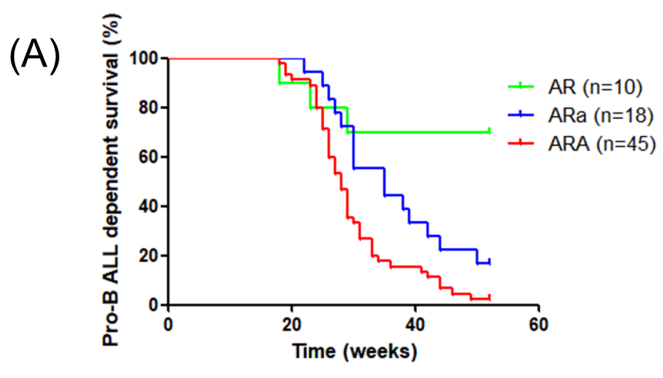

(B)

(E)

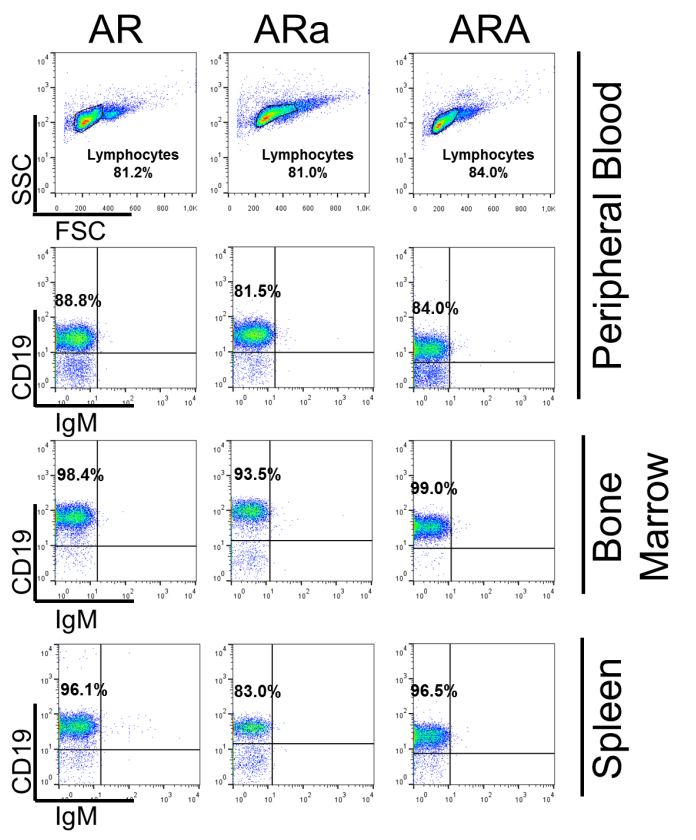

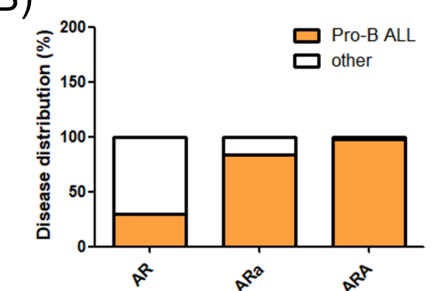

(C)

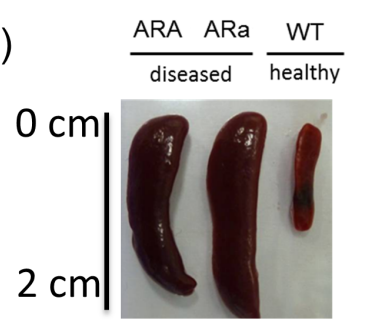

$(\mathrm{F})$

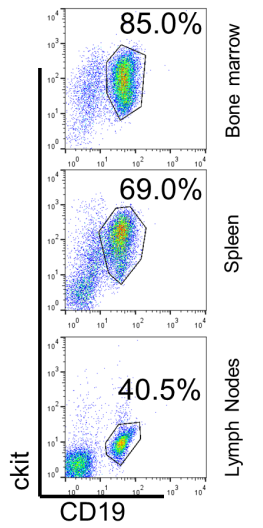

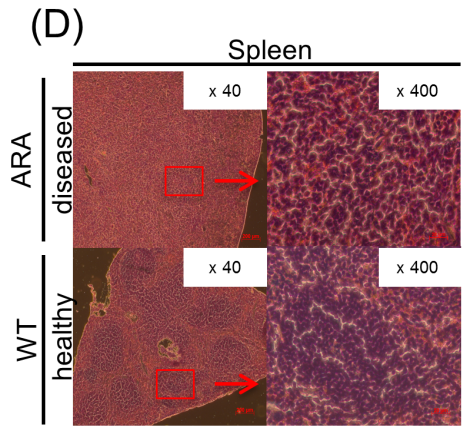

(D)

(G)

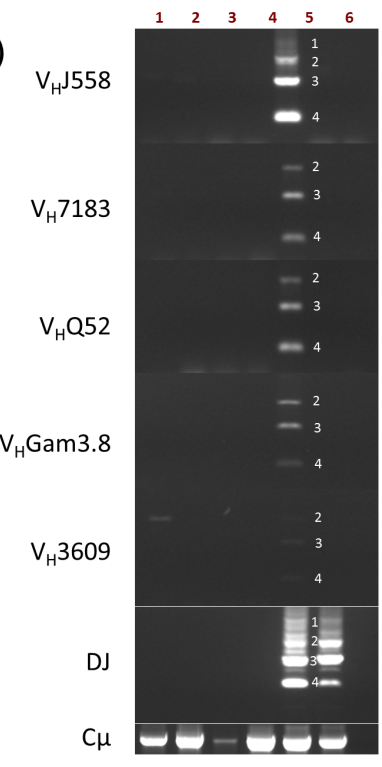

Figure 1: Aid deficiency accelerates pro-B ALL development in $\mathbf{p 1 9 A r f}^{-\boldsymbol{R a g l}^{-/-}}$mice. A. Pro-B-ALL-dependent survival

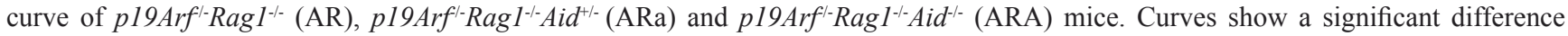
in pro-B-ALL-dependent survival (Log-rank test $p<0.0001$ ). B. Disease distribution of pro-B ALL in AR, ARa and ARA mice. C. Representative splenomegaly of a diseased ARa and ARA mouse, compared to a C57BL/6J wildtype mouse. D. Hematoxylin/Eosin staining from leukemic ARA spleens, showing loss of their architecture due to blast cell infiltration. E. Representative blot of hematopoietic subsets in diseased AR, ARa and ARA mice, showing an accumulation of $\mathrm{CD}_{19} \mathrm{IgM}^{-}$pro-B cells. F. Representative FACS analysis of a nonirradiated C57BL/6J wildtype recipient mouse that was transplanted with leukemic total BM from a diseased ARA donor mouse. Nine days after $\mathrm{BM}$ transplantation, blast cells $\left(\mathrm{CD} 19^{+} \mathrm{ckit}^{+}\right)$are visible in bone narrow, spleen and lymph nodes $(n=2)$. G. Immunoglobulin $\mathrm{V}(\mathrm{D})$ J-recombination in ARa (lanes 1,2) and ARA (lanes 3,4) tissues infiltrated with leukemic blast cells, as analyzed by PCR. Thymocytes (lane 6) serve as negative control and sorted CD19+ B-cells (lane 5) from the spleens of healthy C57BL/6 wildtype mice serve as a control for polyclonal V(D)J-recombination. Infiltrated tissues show only the $\mathrm{c} \mu$ heavy chain. 
in all analyzed pro-B ALLs (Figure 3A, Supplementary Figure 5 and Supplementary Table 2). Although no cancer related genes could be found in the recurrently amplified regions, the analysis validates the integrity of the murine model, since the same aberrations were already described for AR leukemias [30]. Furthermore, the identified cytogenetic abnormality can be contributed to the p19Arf deficiency, since recurrent whole Chr. 14 gains were previously reported in ARFnull lymphomas of E $\mu$-myc transgenic mice and linked to an improved treatment response [31]. To further identify secondary somatically acquired hits, which lead to pro-B ALL development, we performed whole exome sequencing (WES) of three leukemic ARA BM tumor samples, and their corresponding germline DNA, which was extracted from the tail of the respective mouse at first signs of disease. Somatic variants identified by WES ranged from 26 to 195 per mouse, and of these 3 to 12 were deemed tumor specific according to the COSMIC cancer gene consensus list [32]. All three analyzed ARA pro-B ALLs displayed recurrent heterozygous variants in the Jak3 (p.R653H/p.V670A) and Dnm2 gene (p.G397R) (Figure $3 \mathrm{~B} / 3 \mathrm{C}$ ). Sanger sequencing of the hotspot regions in both target genes in an extended cohort of AR, ARa and ARA

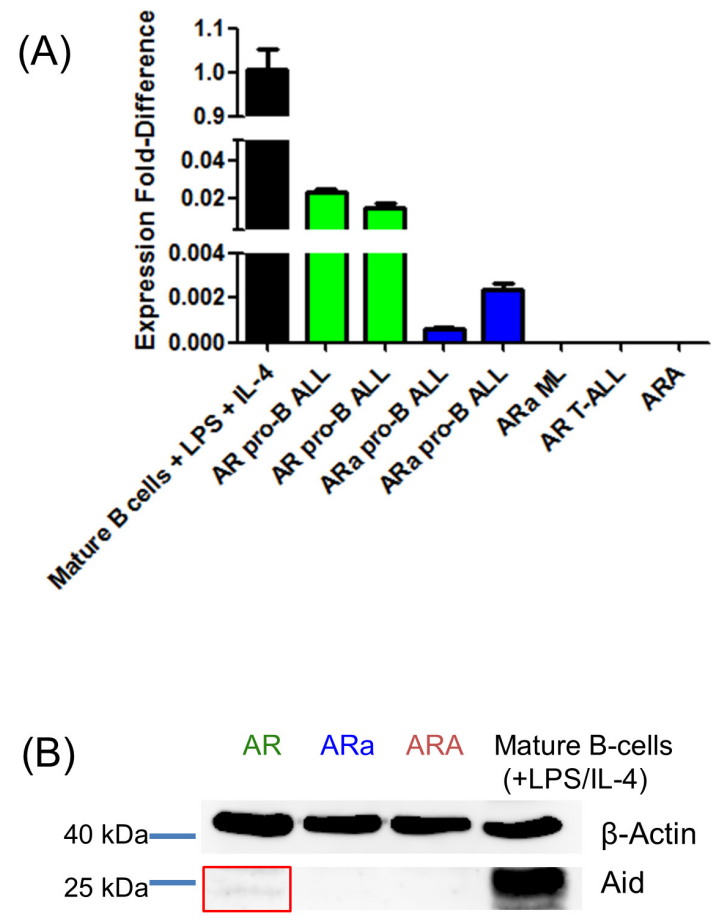

pro-B ALLs, revealed a mutational pattern of somatic Jak3 mutations in $75 \%$ of AR, $61 \%$ of ARa and $79 \%$ of ARA mice (Figure 3D). Moreover, Dnm2 was somatically mutated in close to $100 \%$ of all pro-B ALLs analyzed, with all identified variants located in the middle domain (Figure 3E). Immunoblotting of leukemic AR, ARa and ARA BM samples validated active Stat5 signaling in all three cohorts (Figure 3F), which is in line with the detected activating Jak3 variants [33]. Moreover, it was recently reported for a Lmo2 transgenic mouse model that loss of function mutations in Dnm2 increase the IL-7R cell surface expression, which expands the pool of IL-7 responsive cells [34]. These findings highlight the importance of the IL-7 signaling pathway in pro-B leukemias.

\section{Aid deficiency correlates with enhanced proliferation of healthy pro-B cells in $\operatorname{Rag}^{-1-}$ tumor-prone mice}

Compared to WT mice, ARA and ARa mice showed an accumulation of CD19+ IgM- pro-B cells in the bone marrow (Figure 4A). To analyze whether Aid deficiency
(C)

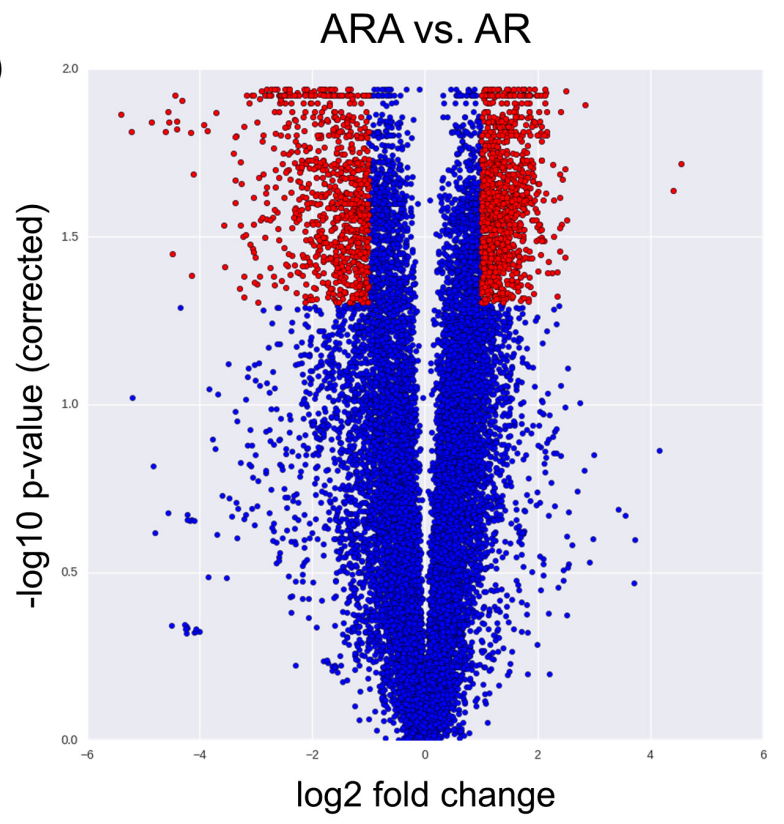

Figure 2: B-cell-specific Aid expression detectable in $1919 \operatorname{Arf}^{\prime}$ Rag $1^{-/-}$mice. A. Quantitative Real-time-PCR analysis showing

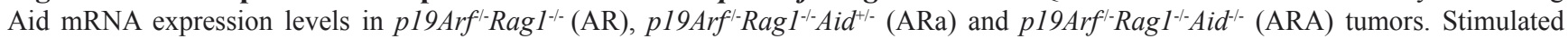
B220 $0^{+}$splenic B-cells (LPS/IL-4) from wildtype mice serve as positive control. Aid expression is detectable in AR and ARa pro-B ALLs, while it is absent in the respective T-ALLs and myeloproliferative diseases (ML) $(n=3)$. B. Immunoblot analysis showing the presence of the Aid protein in AR tumors. Leukemic blast cells of ARA mice serve as a negative control, while stimulated B220 splenic B-cells from wildtype mice were used as a positive control. Beta-Actin serves as a loading control $(n=3)$. C. Microarray analysis results comparing the gene expression between AR and ARA tumor samples, which were visualized in a volcano plot. Red dots have a fold change greater than two and a corrected p-value smaller than 0.05 . Out of the 18465 data points, 823 are lower and 1001 higher in ARA tumor samples relative to AR tumors. 
influences the pro-B cell population in young and healthy AR, ARa and ARA mice, B220 ${ }^{+}$BM B-cells from the respective backgrounds were sorted and cultured in vitro. Since the importance of the IL-7 signaling was highlighted in the somatic mutational spectrum, IL-7 sensitivity assays were performed. Thereby BM pro-B cells of healthy AR, ARa and ARA mice showed significant apoptosis induction (Figure 4B) (AR $p=0.0444$, Ara $p=0.0049$, ARA $p=$ 0.05 ; student's t-test) while differences in IL-7 sensitivity could not be observed between the groups after 24 hours of IL-7 withdrawal (Figure 4C). These results emphasize the strong IL-7 dependency of the Rag1 negative pro-B cells, which interfered with the in vitro simulation of a potential Aid induction in the absence of IL-7 [8]. In this regard, Aicda transcripts were not detectable at 24 or 48 hours after IL-7 depletion in either AR or ARa healthy pro-B cells, even in the presence of LPS as infectious stimulus (data not shown). Nevertheless, the proliferation rate of healthy ARA B220 $0^{+}$B-cells was significantly higher (day $3 p=0.0098$, day4 $p=0.0244$ ) compared to AR B220 ${ }^{+}$B-cells (Figure 4D). This observation extends the findings of Kuraoka et al. [21], stating that Aicd $^{-/-}$progenitors exhibit a significant advantage in the production of immature and mature B-cell compartments. This proliferative increase was further validated by BrdU assays, showing enhanced accumulation of ARA pro-B

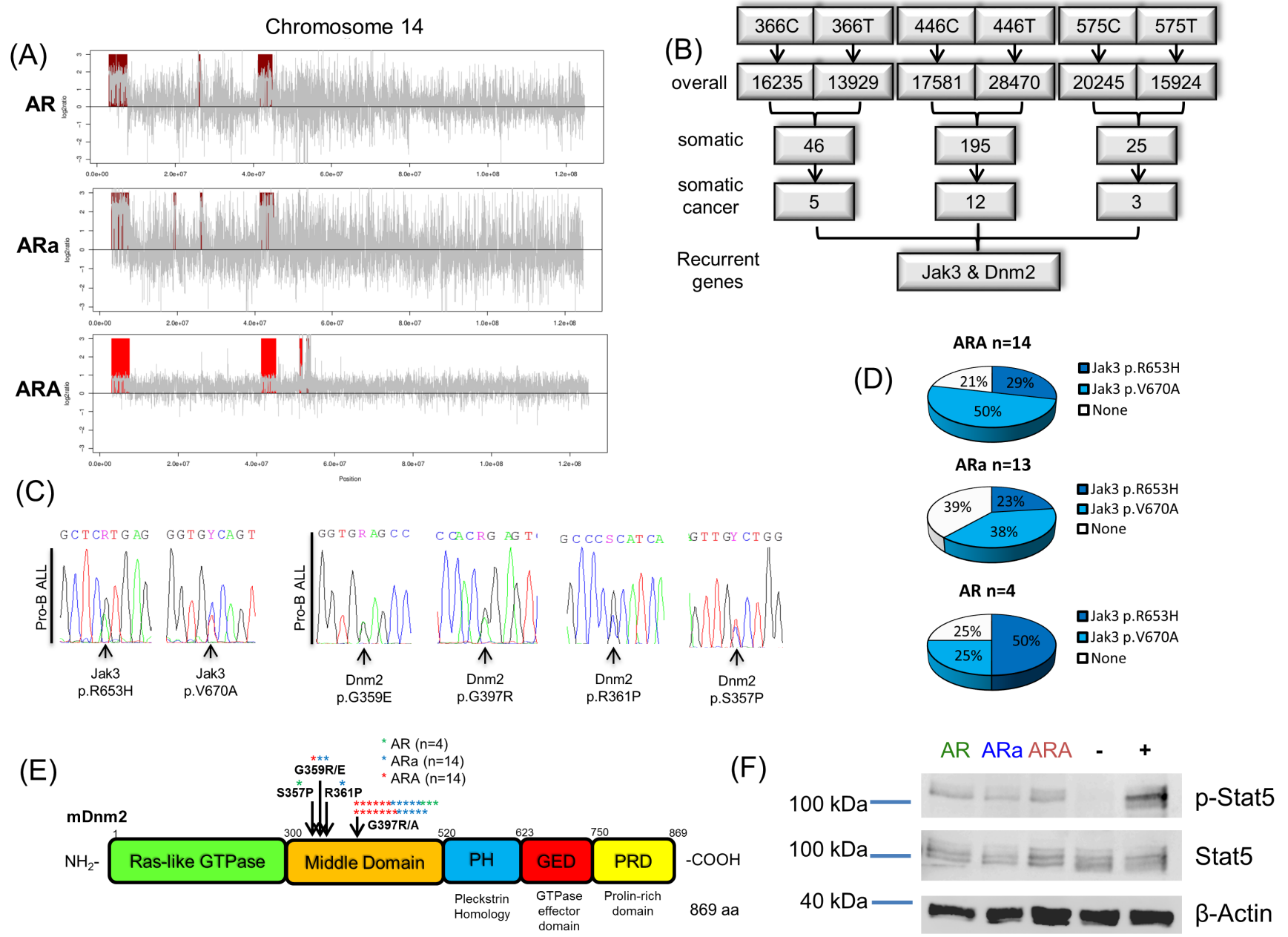

Figure 3: Sequencing of Aid-deficient tumors reveals activating mutations influencing IL-7 signaling. A. From Tumor/

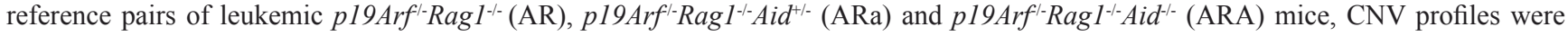
calculated using EXCAVATOR2. A representative plot for each genotype is shown. CNV profiles display recurrent gains (red) of regions on chromosome 14. B. Presentation of WES analysis from three ARA pro-B ALLs. 5-11 of the somatic variants were deemed tumor-specific by MUTECT analysis, with Jak3 and Dnm 2 as recurrent genes. C. Representative chromatogram of Jak3 (p.R653H/p.V670A) and Dnm2 (p.G359E/p.G397R/p.R361P/p.S357P) mutation validation by Sanger sequencing. D. Sanger sequencing results of Jak3 Exon15 show an accumulation of somatic Jak3 p.R653H and p.V670A variants in AR $(n=4)$, ARa $(n=13)$ and ARA $(n=14)$ tumors. E. Sanger sequencing identifies recurrent mutations in the Dnm2 gene affecting the amino acids p.G359R/E, p.R361P, p.S357P and p.G397R/A in AR $(n=4)$, ARa and ARA pro-B ALLs $(n=14)$. F. Immunoblot analysis showing Stat5 phosphorylation in AR, ARa and ARA pro-B ALLs. IL-3 depleted $\mathrm{BaF} 3$ cells serve as negative (-) and $\mathrm{BaF} 3$ cells overexpressing murine Jak3 V670A as positive (+) control. Stat5 and beta-Actin were used as loading controls $(n=3)$. 
cells ( $p=0.0318$, student's t-test; AR $=26.8 \pm 4.8 \%$, ARa $=33.4 \pm 9.2 \%, \mathrm{ARA}=38.5 \pm 12.2 \%$ ) in the DNA synthesis phase (S-phase) (Figure 4E and Supplementary Figure $4 \mathrm{E})$. Since the analyzed pro-B cells are highly IL-7 dependent, we were unable to investigate the observed results with regard to Aid induction in the absence of IL-7.

\section{DISCUSSION}

In the BM, AID induction through inflammatory stimuli drives the clonal evolution of B-ALL [8], while its loss/reduction in immature B-cells [26] interferes with the negative selection at central tolerance checkpoints for the removal of autoreactive B-cells [20-22, 24, 35]. Here, we show that in a mouse model designed for the investigation of arrested pro-B cells, an additional loss of Aid
(A)
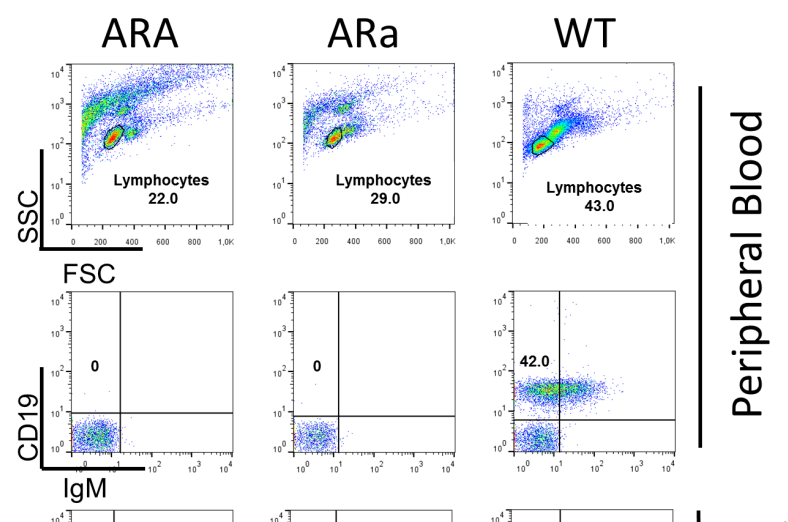

(B)
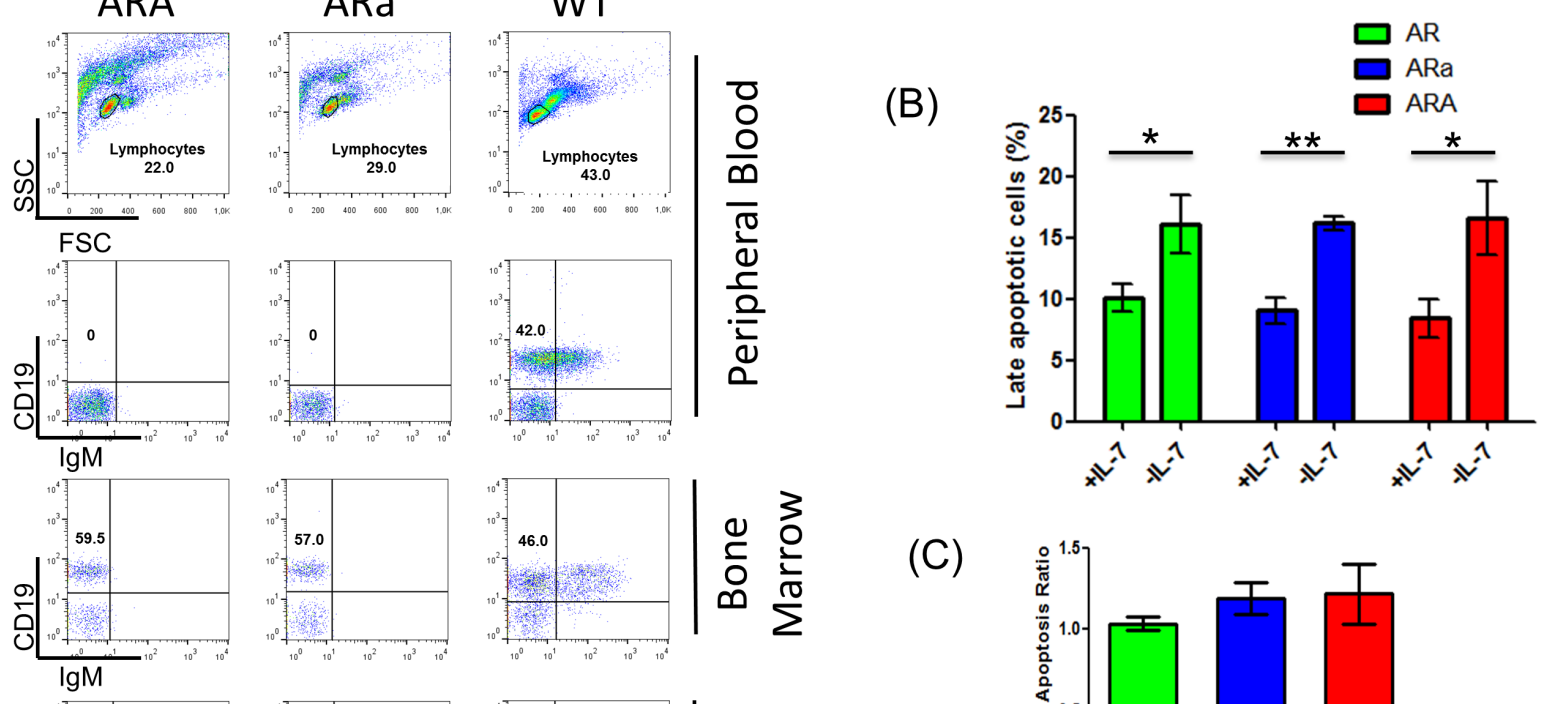

(C)

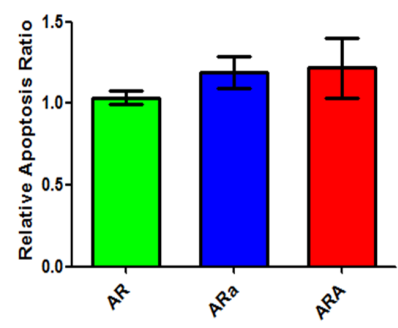

(D)

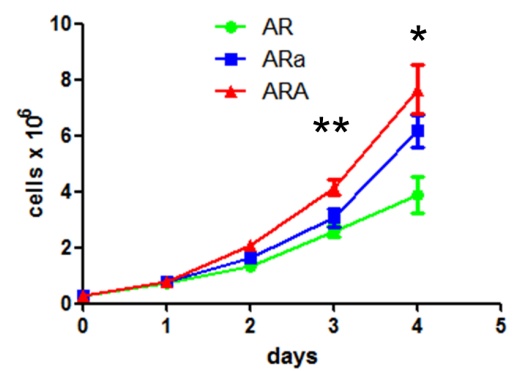

(E)

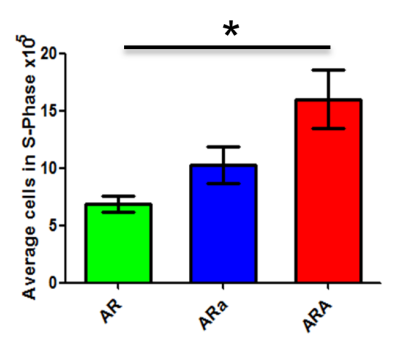

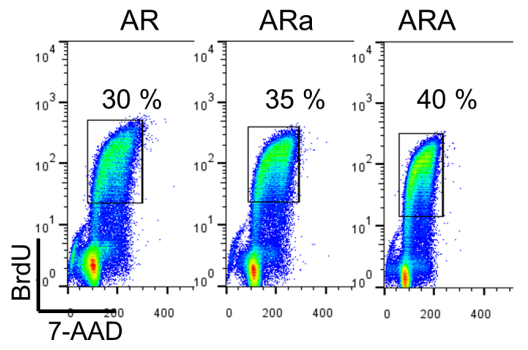

Figure 4: In vitro cultured pro-B cells of healthy $1919 \mathrm{Arf}^{\prime} \operatorname{Rag}^{-/} \mathrm{Aid}^{-/}$mice are highly IL-7 dependent and show an increased proliferative potential compared to their Aid-competent counterparts. A. Representative flow cytometric analysis

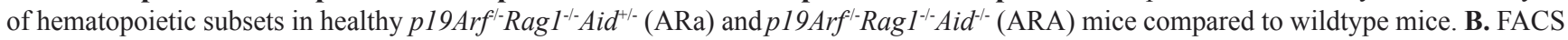
analysis depicting the percentage of cells at a late apoptotic stage $\left(7-\mathrm{AAD}^{+} \mathrm{Annexin}{ }^{+}\right)$from healthy $\mathrm{p} 19 \mathrm{Arf}^{\prime-} \operatorname{Rag} 1^{-\leftarrow}$ (AR), ARa and ARA pro-B cells cultured in vitro after 24 hours of IL-7 withdrawal. All groups show significant late apoptosis induction as calculated by student's t-test (AR $p=0.0444 ;$ ARa $p=0.0049$; ARA $p=0.05 ; n=3$ for AR/ARa; $n=4$ for ARA). C. FACS analysis showing the relative apoptosis ratio of healthy AR, ARa and ARA pro-B cells after 24 hours of IL-7 depletion. Therefore, the ratio between 7-AAD/Annexin double positive cells between the groups in IL-7+ and IL-7- conditions was calculated and the AR ratio set to 1 . No significant differences in IL-7 sensitivity were observed between the groups ( $n=3$ for AR/ARA; $n=4$ for ARA). D. Proliferation curve of healthy AR, ARa and ARA pro-B cells. Compared to AR cells, ARA cells show significantly increased proliferation on day $3(p=0.0098)$ and day $4(p=0.0244)$ as calculated by student's t-test. E. Representative FACS analysis and blot showing cell cycle distribution of healthy AR, ARa and ARA pro-B cells after 1 hour of BrdU pulse labeling. ARA pro-B cells display increased accumulation of cells in the S-phase compared to AR pro-B cells (student's t-test, $p=0.0318 ; n=3$ for AR/ ARA; $n=4$ for ARA). 
accelerated the pro-B ALL incidence from $30 \%$ to $98 \%$. This effect was dose dependent, since Aid heterozygous mice on the same background displayed significant disease reduction, which is in line with a previous report on Aid haploinsufficiency [36]. Moreover, these findings are in agreement with results from Cantaert et al., showing that AID gene dosage regulates central B-cell tolerance in humans [26]. AID-mediated CSR can be actively induced in B-cell precursors in vivo and in vitro [27, 37-39], which further suggests that the function of AID is also preserved at the pro-B cell stage. The fact that the Aid-competent mice in our model were more protected against pro-B ALL development highlights a so far unreported mechanism of functional Aid up-regulation in pro-B cells in the process of malignant transformation. While it was previously reported that physiologic Rag1 expression slows down leukemogenesis in p19Arf-deficient mice [30], our data extend these findings to Aid and suggest that both Rag1 and Aid act as negative regulators in pro-B cells.

In normal pro-B and pre-BI cells AID and RAG1 are repressed by IL-7R-signaling (active JAK-STAT/PI3KAKT) [40-42], since both AID and RAG1 can induce negative selection and cell death at this early B-cell stage $[8,25]$. Nevertheless, pro-B ALL tumors in AR mice displayed significant Aid upregulation. This detectable Aid expression and the fact that Aid deficiency lead to a dosedependent pro-B ALL acceleration, suggests a mechanism that is similar to the clearance of autoreactive cells to establish central tolerance via Aid induced DNA damage and subsequent p53-mediated induction of cell death [26, 43]. In our model, we extend this role of Aid to arrested pre-leukemic pro-B cells which have not yet undergone Rag1 mediated V(D)J-recombination.

Although it was shown that the IL-7R safeguards pre-B cells against premature AID activation [8], pro-B cells oscillate between IL-7R high and low states [40]. Since the Rag1 negative pro-B cell arrested population in our model is highly susceptible to IL-7 exhaustion and subsequent cell death, disruption of IL-7R signaling could enable the Aid expression necessary to clear Rag1 deficient pre-leukemic clones, which would be a mechanistic explanation for the dose-dependent pro-B ALL acceleration in Aid deficient counterparts. The fact that low levels of pro-B ALL development can be observed in AR mice even in the presence of Aid can be accounted for by the acquisition of pro-survival mutations affecting the IL-7R pathway. To that effect, whole exome sequencing of AR, ARa and ARA pro-B ALLs identified highly recurrent somatic mutations in both Dnm2 and Jak3. Loss of function mutations in Dnm2 have recently been linked to increased IL-7R density on the surface of murine Lmo2 transgenic T-ALLs [34]. By up-regulating IL-7R surface expression, arrested pro-B cells could respond to limited IL-7 availability, due to aberrant accumulation and increased consumption [44]. Additional mutations in Jak3 p.R653H and p.V670A, which confer constitutive active downstream signaling via pStat5 and arise shortly before blast propagation [33], render the cells IL-7 independent and counteract the negative regulation imposed by Aid.

The observation that $\mathrm{B} 220^{+}$sorted cells from healthy ARA mice showed increased proliferative potential, when compared to Aid competent AR mice, suggests that loss of Aid already affects certain intrinsic cell properties of IL-7 dependent pro-B cells. So far, increased proliferation of Aid-deficient cells has been shown to be significant in immature B-cells, which displayed an advantage through increased self-renewal capacity, seen by comparing Aicda $^{+/+}$against Aicda ${ }^{-/-}$stem cell populations [21]. Therefore, it will be interesting to explain these in vitro results by elucidating the differences between healthy AR and ARA pro-B cells on a general gene expression level, or even on an epigenetic basis.

While it was previously shown that AID expression is regulated by PI3K [45], these findings were recently extended further by uncovering that PI $3 \mathrm{~K} \gamma \delta$ or Bruton's kinase inhibitor treatment of mature B-cells leads to enhanced AID expression, which causes increased genomic instability [46]. Combining these insights with our own data highlights the importance of a tightly regulated Aid expression during the life of a B-cell. While loss of Aid in pro-B cells promoted pro-B ALL in our model and is known to impair central B-cell tolerance in immature B-cells [26], its upregulation contributes to the clonal evolution of leukemia in small pre-BII cells [8] and can induce genomic instability in mature B-cells [46].

In summary, we propose Aid as a negative regulator in Rag1 deficient pro-B cells, whereby Aid clears aberrant pro-B cells that are leukemia prone. Therefore, we extend the role of Aid in clearing autoreactive B-cells to establish $\mathrm{B}$-cell tolerance, to the negative regulation of pro-B cells that are susceptible to malignant transformation in the specific context of Rag1 deficiency and pro-B ALL development.

\section{MATERIALS AND METHODS}

\section{Generation of $p 19 \operatorname{Arf}^{-1 /} / \operatorname{Rag} 1^{-/ /} / \operatorname{Aid}^{-/-}$mice}

The $p 19 \mathrm{Arf}^{/-} / \operatorname{Rag} 1^{-/-}$mice were generously provided by Marina Cavazzana [30], Imagine, Paris and crossed back on Aid deficient mice [16] kindly provided by Tasuku Honjo, to obtain the mouse cohorts $p 19 \mathrm{Arf}^{-/} / \operatorname{Rag}^{-/-} / \mathrm{Aid}^{-}$ /. and p19Arf $^{/ /} / \operatorname{Rag} 1^{-/ /} / \mathrm{Aid}^{+/}$. Recipient C57BL/6 wildtype mice were obtained from Janvier Laboratories. Animals were housed in a specific, pathogen-free animal facility at the ZETT/Heinrich-Heine University Duesseldorf and experiments were performed in compliance with the German State Agency for Nature, Environment and Consumer Protection (LANUV). 


\section{Cell culture}

Iscove's modified Dulbecco's medium supplemented with $50 \mu \mathrm{M} \beta$-mercaptoethanol, $1 \mathrm{mM}$ L-glutamine, $2 \%$ heat-inactivated fetal calf serum, $1 \mathrm{mM}$ penicillinstreptomycin (Life Technologies) and $0.03 \%(\mathrm{w} / \mathrm{v})$ primatone RL (Sigma) was used for pro-B cell culture experiments. Pro-B cells isolated by MACS-sorting for $\mathrm{B} 220^{+}$(Miltenyi Biotec) from mouse BM were cultured on Mitomycin-C-treated ST2 feeder cells in IMDM medium containing IL-7 (5 ng/ml) (R\&D Systems).

\section{Proliferation \& BrdU assay}

$3 \times 10^{5}$ healthy pro-B cells of $p 19 \operatorname{Arf}^{\prime}$ Rag $1^{-/}$, p19Arf ${ }^{-} \mathrm{Ragl}^{-/} \mathrm{Aid}^{+/-}$and $\mathrm{plOArf}^{\prime} \mathrm{Ragl}^{-/} \mathrm{Aid}^{-/}$mice were seeded on day 1 in a 6-well plate. Cell numbers were determined every 24 hours using a Vi-Cell XR (Beckman Coulter). Cells from day 3 were further analyzed for proliferation with the FITC BrdU Flow Kit (BD Biosciences). The cells were pulse labeled with BrdU for 1 hour and analyzed on a FACSCalibur ${ }^{\mathrm{TM}}$ Flow Cytometer according to the manufacturer's protocol (ARA $n=4$, ARa $n=3$, AR $n=$ 3; biological replicates).

\section{Immunoblot analysis}

Leukemic bone barrow cells from $p 19 \operatorname{Arf}^{\prime /}$ Rag $1^{-/}$,

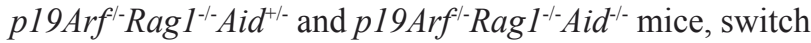
culture stimulated spleen cells from WT C57BL/6 mice (LPS $(20 \mu \mathrm{g} / \mathrm{ml})+$ IL4 $(25 \mathrm{ng} / \mathrm{ml})$ treatment for 4 days) or $\mathrm{BaF} 3$ cells (with and without expression of murine Jak3 V670A and after 4h of IL-3 depletion) were lysed in RIPA buffer (50 mM Tris pH 8.0, $150 \mathrm{mM} \mathrm{NaCl}, 0,5$ $\%$ Sodiumdeoxycholate, $1 \%$ NP-40 substitute, 0,1\% SDS) containing protease/phosphatase inhibitors (Roche Diagnostics). Immunoblotting was carried out using the following antibodies: anti-AID clone L7E7 1:1000 (Cell Signaling), anti-phospho-Stat5 D47E7 (Tyr694) 1:1000 (Cell Signaling), anti-Stat5 1:1000 (Cell Signaling) and anti- $\beta$-Actin clone AC-74 1:10000 (Sigma-Aldrich). Detection was carried out using anti-mouse horseradish peroxidase conjugates (Santa Cruz Biotechnology) with an ECL system (Thermo Scientific) $(n=3)$.

\section{ACKNOWLEDGMENTS}

The authors would like to thank all members of our groups.

\section{CONFLICTS OF INTEREST}

The authors declare no potential conflicts of interest.

\section{GRANT SUPPORT}

J. Hauer has been supported by the German Cancer Foundation (110997), DJCLS02R/2016, KKS A2016/07 and from the "Forschungskommission" of the medical faculty of the Heinrich Heine University. A. Borkhardt has been supported by the German Children's Cancer Foundation and the Federal Ministry of Education and Research, Bonn, Germany. Research in I. Sánchez-García's group is partially supported by FEDER and by MINECO (SAF2012-32810, SAF201564420-R and Red de Excelencia Consolider OncoBIO SAF2014-57791-REDC), Instituto de Salud Carlos III (PIE14/00066), ISCIII- Plan de Ayudas IBSAL 2015 Proyectos Integrados (IBY15/00003), by Junta de Castilla y León (BIO/SA51/15, CSI001 U14, UIC-017, and CSI001U16), Fundacion Inocente Inocente and by the ARIMMORA project (European Union's Seventh Framework Programme (FP7/2007-2013) under grant agreement no. 282891). I. Sánchez-García's lab is a member of the EuroSyStem and the DECIDE Network funded by the European Union under the FP7 program. A. Borkhardt and I. Sánchez-García have been supported by the German Carreras Foundation (DJCLS R13/26). Research in C. Vicente-Dueñas' group is partially supported by a "Miguel Servet" Grant (CP14/00082 AES 2013-2016 - FEDER) from the Instituto de Salud Carlos III (Ministerio de Economía y Competitividad) and by the Lady Tata International Award for Research in Leukaemia 2016-2017. A. Martín-Lorenzo was supported by FSE-Conserjería de Educación de la Junta de Castilla y León (CSI001-13).

\section{Editorial note}

This paper has been accepted based in part on peerreview conducted by another journal and the authors' response and revisions as well as expedited peer-review in Oncotarget.

\section{REFERENCES}

1. Zhang J, McCastlain K, Yoshihara H, Xu B, Chang Y, Churchman ML, Wu G, Li Y, Wei L, Iacobucci I, Liu Y, Qu C, Wen J, et al. Deregulation of DUX4 and ERG in acute lymphoblastic leukemia. Nat Genet. 2016; 48: 1481-9. http://doi.org/10.1038/ng.3691.

2. Hunger SP, Mullighan CG. Acute Lymphoblastic Leukemia in Children. N Engl J Med. 2015; 373: 1541-52. http://doi. org/10.1056/NEJMra1400972.

3. Pui CH, Yang JJ, Hunger SP, Pieters R, Schrappe M, Biondi A, Vora A, Baruchel A, Silverman LB, Schmiegelow K, Escherich G, Horibe K, Benoit YC, et al. Childhood Acute Lymphoblastic Leukemia: Progress Through Collaboration. J Clin Oncol. 2015; 33: 2938-48. http://doi.org/10.1200/ 
JCO.2014.59.1636.

4. Mullighan CG, Goorha S, Radtke I, Miller CB, CoustanSmith E, Dalton JD, Girtman K, Mathew S, Ma J, Pounds $\mathrm{SB}, \mathrm{Su} \mathrm{X}$, Pui CH, Relling MV, et al. Genome-wide analysis of genetic alterations in acute lymphoblastic leukaemia. Nature. 2007; 446: 758-64. http://doi. org/10.1038/nature05690.

5. Shah S, Schrader KA, Waanders E, Timms AE, Vijai J, Miething C, Wechsler J, Yang J, Hayes J, Klein RJ, Zhang J, Wei L, Wu G, et al. A recurrent germline PAX5 mutation confers susceptibility to pre-B cell acute lymphoblastic leukemia. Nat Genet. 2013; 45: 1226-31. http://doi. org/10.1038/ng.2754.

6. Papaemmanuil E, Rapado I, Li Y, Potter NE, Wedge DC, Tubio J, Alexandrov LB, Van Loo P, Cooke SL, Marshall J, Martincorena I, Hinton J, Gundem G, et al. RAG-mediated recombination is the predominant driver of oncogenic rearrangement in ETV6-RUNX1 acute lymphoblastic leukemia. Nat Genet. 2014; 46: 116-25. http://doi. org/10.1038/ng.2874.

7. Tsai AG, Lu H, Raghavan SC, Muschen M, Hsieh CL, Lieber MR. Human chromosomal translocations at $\mathrm{CpG}$ sites and a theoretical basis for their lineage and stage specificity. Cell. 2008; 135: 1130-42. http://doi. org/10.1016/j.cell.2008.10.035.

8. Swaminathan S, Klemm L, Park E, Papaemmanuil E, Ford A, Kweon SM, Trageser D, Hasselfeld B, Henke N, Mooster J, Geng H, Schwarz K, Kogan SC, et al. Mechanisms of clonal evolution in childhood acute lymphoblastic leukemia. Nat Immunol. 2015; 16: 766-74. http://doi.org/10.1038/ni.3160.

9. Mullighan CG, Su X, Zhang J, Radtke I, Phillips LA, Miller CB, Ma J, Liu W, Cheng C, Schulman BA, Harvey RC, Chen IM, Clifford RJ, et al. Deletion of IKZF1 and prognosis in acute lymphoblastic leukemia. N Engl J Med. 2009; 360: 470-80. http://doi.org/10.1056/ NEJMoa0808253.

10. Iacobucci I, Li Y, Roberts KG, Dobson SM, Kim JC, Payne-Turner D, Harvey RC, Valentine M, McCastlain K, Easton J, Yergeau D, Janke LJ, Shao Y, et al. Truncating Erythropoietin Receptor Rearrangements in Acute Lymphoblastic Leukemia. Cancer Cell. 2016; 29: 186-200. http://doi.org/10.1016/j.ccell.2015.12.013.

11. Teng G, Maman Y, Resch W, Kim M, Yamane A, Qian J, Kieffer-Kwon KR, Mandal M, Ji Y, Meffre E, Clark MR, Cowell LG, Casellas R, et al. RAG Represents a Widespread Threat to the Lymphocyte Genome. Cell. 2015; 162: 751-65. http://doi.org/10.1016/j.cell.2015.07.009.

12. Mullighan CG, Phillips LA, Su X, Ma J, Miller CB, Shurtleff SA, Downing JR. Genomic analysis of the clonal origins of relapsed acute lymphoblastic leukemia. Science. 2008; 322: 1377-80. http://doi.org/10.1126/ science. 1164266 .

13. Oettinger MA, Schatz DG, Gorka C, Baltimore D. RAG1 and RAG-2, adjacent genes that synergistically activate
V(D)J recombination. Science. 1990; 248: 1517-23.

14. Muramatsu M, Sankaranand VS, Anant S, Sugai M, Kinoshita K, Davidson NO, Honjo T. Specific expression of activation-induced cytidine deaminase (AID), a novel member of the RNA-editing deaminase family in germinal center B cells. J Biol Chem. 1999; 274: 18470-6.

15. Maul RW, Gearhart PJ. AID and somatic hypermutation. Adv Immunol. 2010; 105: 159-91. http://doi.org/10.1016/ S0065-2776(10)05006-6.

16. Muramatsu M, Kinoshita K, Fagarasan S, Yamada S, Shinkai Y, Honjo T. Class switch recombination and hypermutation require activation-induced cytidine deaminase (AID), a potential RNA editing enzyme. Cell. 2000; 102: 553-63.

17. Adams JM, Gerondakis S, Webb E, Corcoran LM, Cory $\mathrm{S}$. Cellular myc oncogene is altered by chromosome translocation to an immunoglobulin locus in murine plasmacytomas and is rearranged similarly in human Burkitt lymphomas. Proc Natl Acad Sci U S A. 1983; 80: 1982-6.

18. Klein IA, Resch W, Jankovic M, Oliveira T, Yamane A, Nakahashi H, Di Virgilio M, Bothmer A, Nussenzweig A, Robbiani DF, Casellas R, Nussenzweig MC. Translocationcapture sequencing reveals the extent and nature of chromosomal rearrangements in B lymphocytes. Cell. 2011; 147: 95-106. http://doi.org/10.1016/j.cell.2011.07.048.

19. Klemm L, Duy C, Iacobucci I, Kuchen S, von Levetzow G, Feldhahn N, Henke N, Li Z, Hoffmann TK, Kim YM, Hofmann WK, Jumaa H, Groffen J, et al. The B cell mutator AID promotes B lymphoid blast crisis and drug resistance in chronic myeloid leukemia. Cancer Cell. 2009; 16: 23245. http://doi.org/10.1016/j.ccr.2009.07.030.

20. Kuraoka M, Snowden PB, Nojima T, Verkoczy L, Haynes BF, Kitamura D, Kelsoe G. BCR and Endosomal TLR Signals Synergize to Increase AID Expression and Establish Central B Cell Tolerance. Cell Rep. 2017; 18: 1627-35. http://doi.org/10.1016/j.celrep.2017.01.050.

21. Kuraoka M, Holl TM, Liao D, Womble M, Cain DW, Reynolds AE, Kelsoe G. Activation-induced cytidine deaminase mediates central tolerance in B cells. Proc Natl Acad Sci U S A. 2011; 108: 11560-5. http://doi. org/10.1073/pnas.1102571108.

22. Meyers G, Ng YS, Bannock JM, Lavoie A, Walter JE, Notarangelo LD, Kilic SS, Aksu G, Debre M, RieuxLaucat F, Conley ME, Cunningham-Rundles C, Durandy A, et al. Activation-induced cytidine deaminase (AID) is required for B-cell tolerance in humans. Proc Natl Acad Sci U S A. 2011; 108: 11554-9. http://doi.org/10.1073/ pnas. 1102600108 .

23. Chen L, Guo L, Tian J, Zheng B, Han S. Deficiency in activation-induced cytidine deaminase promotes systemic autoimmunity in lpr mice on a C57BL/6 background. Clin Exp Immunol. 2010; 159: 169-75. http://doi.org/10.1111/ j.1365-2249.2009.04058.x.

24. Durandy A, Cantaert T, Kracker S, Meffre E. Potential roles 
of activation-induced cytidine deaminase in promotion or prevention of autoimmunity in humans. Autoimmunity. 2013; 46: 148-56. http://doi.org/10.3109/08916934.2012.7 50299.

25. Muto T, Okazaki IM, Yamada S, Tanaka Y, Kinoshita K, Muramatsu M, Nagaoka H, Honjo T. Negative regulation of activation-induced cytidine deaminase in B cells. Proc Natl Acad Sci U S A. 2006; 103: 2752-7. http://doi.org/10.1073/ pnas.0510970103.

26. Cantaert T, Schickel JN, Bannock JM, Ng YS, Massad C, Oe T, Wu R, Lavoie A, Walter JE, Notarangelo LD, Al-Herz W, Kilic SS, Ochs HD, et al. ActivationInduced Cytidine Deaminase Expression in Human B Cell Precursors Is Essential for Central B Cell Tolerance. Immunity. 2015; 43: 884-95. http://doi.org/10.1016/j. immuni.2015.10.002.

27. Mao C, Jiang L, Melo-Jorge M, Puthenveetil M, Zhang X, Carroll MC, Imanishi-Kari T. T cell-independent somatic hypermutation in murine $\mathrm{B}$ cells with an immature phenotype. Immunity. 2004; 20: 133-44.

28. Ueda Y, Liao D, Yang K, Patel A, Kelsoe G. T-independent activation-induced cytidine deaminase expression, class-switch recombination, and antibody production by immature/transitional 1 B cells. J Immunol. 2007; 178: 3593-601.

29. Mombaerts P, Iacomini J, Johnson RS, Herrup K, Tonegawa S, Papaioannou VE. RAG-1-deficient mice have no mature B and T lymphocytes. Cell. 1992; 68: 869-77.

30. Hauer J, Mullighan C, Morillon E, Wang G, Bruneau J, Brousse N, Lelorc'h M, Romana S, Boudil A, Tiedau D, Kracker S, Bushmann FD, Borkhardt A, et al. Loss of p19Arf in a Rag1(-/-) B-cell precursor population initiates acute B-lymphoblastic leukemia. Blood. 2011; 118: 544-53. http://doi.org/10.1182/blood-2010-09-305383.

31. Helmrich A, Lee S, O'Brien P, Dorken B, Lowe SW, Schrock E, Schmitt CA. Recurrent chromosomal aberrations in INK4a/ARF defective primary lymphomas predict drug responses in vivo. Oncogene. 2005; 24: 4174-82. http://doi. org/10.1038/sj.onc.1208600.

32. Forbes SA, Beare D, Gunasekaran P, Leung K, Bindal N, Boutselakis H, Ding M, Bamford S, Cole C, Ward S, Kok CY, Jia M, De T, et al. COSMIC: exploring the world's knowledge of somatic mutations in human cancer. Nucleic Acids Res. 2015; 43: D805-11. http://doi.org/10.1093/nar/ gku1075.

33. Martin-Lorenzo A, Hauer J, Vicente-Duenas C, Auer F, Gonzalez-Herrero I, Garcia-Ramirez I, Ginzel S, Thiele R, Constantinescu SN, Bartenhagen C, Dugas M, Gombert M, Schafer D, et al. Infection Exposure is a Causal Factor in B-cell Precursor Acute Lymphoblastic Leukemia as a Result of Pax5-Inherited Susceptibility. Cancer Discov. 2015; 5: 1328-43. http://doi.org/10.1158/2159-8290.CD15-0892.

34. Tremblay CS, Brown FC, Collett M, Saw J, Chiu SK,
Sonderegger SE, Lucas SE, Alserihi R, Chau N, Toribio ML, McCormack MP, Chircop M, Robinson PJ, et al. Loss-of-function mutations of Dynamin 2 promote T-ALL by enhancing IL-7 signalling. Leukemia. 2016. http://doi. org/10.1038/leu.2016.100.

35. Meffre E, Casellas R, Nussenzweig MC. Antibody regulation of B cell development. Nat Immunol. 2000; 1: 379-85. http://doi.org/10.1038/80816.

36. Sernandez IV, de Yebenes VG, Dorsett Y, Ramiro AR. Haploinsufficiency of activation-induced deaminase for antibody diversification and chromosome translocations both in vitro and in vivo. PLoS One. 2008; 3: e3927. http:// doi.org/10.1371/journal.pone.0003927.

37. Rolink A, Melchers F, Andersson J. The SCID but not the RAG-2 gene product is required for $\mathrm{S}$ mu-S epsilon heavy chain class switching. Immunity. 1996; 5: 319-30.

38. Han JH, Akira S, Calame K, Beutler B, Selsing E, Imanishi-Kari $\mathrm{T}$. Class switch recombination and somatic hypermutation in early mouse B cells are mediated by B cell and Toll-like receptors. Immunity. 2007; 27: 64-75. http:// doi.org/10.1016/j.immuni.2007.05.018.

39. Seagal J, Edry E, Keren Z, Leider N, Benny O, Machluf M, Melamed D. A fail-safe mechanism for negative selection of isotype-switched B cell precursors is regulated by the Fas/FasL pathway. J Exp Med. 2003; 198: 1609-19. http:// doi.org/10.1084/jem.20030357.

40. Clark MR, Mandal M, Ochiai K, Singh H. Orchestrating B cell lymphopoiesis through interplay of IL-7 receptor and pre-B cell receptor signalling. Nat Rev Immunol. 2014; 14 : 69-80. http://doi.org/10.1038/nri3570.

41. Johnson K, Hashimshony T, Sawai CM, Pongubala JM, Skok JA, Aifantis I, Singh H. Regulation of immunoglobulin light-chain recombination by the transcription factor IRF-4 and the attenuation of interleukin-7 signaling. Immunity. 2008; 28: 335-45. http:// doi.org/10.1016/j.immuni.2007.12.019.

42. Ochiai K, Maienschein-Cline M, Mandal M, Triggs JR, Bertolino E, Sciammas R, Dinner AR, Clark MR, Singh H. A self-reinforcing regulatory network triggered by limiting IL-7 activates pre-BCR signaling and differentiation. Nat Immunol. 2012; 13: 300-7. http://doi.org/10.1038/ni.2210.

43. Kuraoka M, Kelsoe G. A novel role for activation-induced cytidine deaminase: central B-cell tolerance. Cell Cycle. 2011; 10: 3423-4. http://doi.org/10.4161/cc.10.20.17693.

44. Corfe SA, Paige CJ. The many roles of IL-7 in B cell development; mediator of survival, proliferation and differentiation. Semin Immunol. 2012; 24: 198-208. http:// doi.org/10.1016/j.smim.2012.02.001.

45. Omori SA, Cato MH, Anzelon-Mills A, Puri KD, ShapiroShelef M, Calame K, Rickert RC. Regulation of classswitch recombination and plasma cell differentiation by phosphatidylinositol 3-kinase signaling. Immunity. 2006; 25: 545-57. http://doi.org/10.1016/j.immuni.2006.08.015. 
46. Compagno M, Wang Q, Pighi C, Cheong TC, Meng FL, Poggio T, Yeap LS, Karaca E, Blasco RB, Langellotto F, Ambrogio C, Voena C, Wiestner A, et al. Phosphatidylinositol 3-kinase delta blockade increases genomic instability in B cells. Nature. 2017; 542: 489-93. http://doi.org/10.1038/nature21406. 